Premeditation Engenders False Perceptions of Personal Control 1

Perish the Forethought:

Premeditation Engenders Misperceptions of Personal Control

\author{
Carey K. Morewedge \\ Department of Social and Decision Sciences, Carnegie Mellon University
}

Kurt Gray and Daniel M. Wegner

Department of Psychology, Harvard University

To appear in: R. Hassin, K. Oschsner, \& Y. Trope (Eds.), Self control in society, mind, and brain. Oxford University Press. 


\begin{abstract}
People are normally encouraged to engage in premeditation- to think about the potential consequences of their behavior before acting. Indeed, planning, considering, and studying can be important precursors to decision making, and often seem to be essential to effective action. This view of premeditation is shared by most humans, a kind of universal ideal, and it carries an additional interesting implication: Even the hint that premeditation occurred can serve as a potent cue indicating voluntary action, both to actors and observers. In legal and moral contexts, for example, actors are seen as especially culpable for the consequences of their actions if those consequences were premeditated, whether or not the premeditation influenced the decision. In this chapter, we review evidence indicating that the perception of premeditation itself can lead people to think that an action's consequences are under personal control, and that this occurs even when the premeditation is irrelevant to the production of the consequences. We present research exploring how various forms of perceived premeditation-including foresight, effortful forethought, wishful thinking, and the consideration of multiple possible outcomes of action—may lead actors to prefer and feel responsible for action outcomes even when this premeditation has no causal relation to the outcomes.
\end{abstract}


“Except only the defendant's intention to produce a given result, no other consideration has affected our feeling that it is or is not just to hold him responsible for the result as its foreseeability."

- Edgerton, (1929, p. 1134). Legal Cause. Harper and James. (cited by Hart \& Honoré, 1959/2002, pp. 254)

It feels necessary to think carefully before making important decisions. Whether buying a house, picking a spouse, or deciding to have children, it seems unwise to make a decision quickly, or to simply pick the first option we considered. Even relatively inconsequential choices are preceded by significant forethought. When buying a new digital camera, for example, we might read Consumer Reports, compare features such as lenses and weight, and try to imagine which would be better suited for our next family gathering or vacation. We engage in such forethought because premeditated decisionschoices guided by prior conscious deliberation of alternatives and their consequencesare considered superior to decisions made on the fly or in its absence. ${ }^{1}$ Our parents, teachers, and peers continually advise us to "Look before you leap," and "Think before you speak," and when we make poor choices, they are often attributed to errors committed during premeditation (“What on Earth was I thinking?”). Premeditated decisions appear to determine the behavior most under our control, and behavior we control is presumed to be better than behavior we do not. Furthermore, both the legal system and society at large view the presence of premeditation as the most important indicator of rational action (Denno, 2003). 
Premeditation plays an important role in classic self-control dilemmas such as deciding whether to spend or to save, eat or diet, and engage in risky or safe behavior. Its presence suggests that not only were we aware of the consequences of our behavior, but we had the power to act rationally and control that behavior. Consequently, we blame ourselves more when lapses in self-control were premeditated than when they were not premeditated (Klimchuck, 1994). Impulsively buying a new car may seem rash, whereas impulsively buying a new car after also considering putting the money aside for our child's college education seems rash and perhaps shameful. Deciding to order steak tartare seems like a mild indulgence, whereas ordering that steak after considering healthier options seems both indulgent and irresponsible. This is also true when viewing the actions of others, as we sympathize less with those who are injured if they had consciously considered (and then ignored) ways to protect themselves in advance (e.g., wearing a helmet). No matter what the domain, it appears that the presence of premeditation is an important indicator of the extent to which people possess self-control.

Determining whether an act was premeditated is considered to be one of the principle tasks, if not the primary task, of modern legal systems (Denno, 2003). When a person is tried for a crime, juries are asked to determine the fulfillment of two criteria: Actus reus and mens rea. Actus reus, or 'guilty act,' refers to whether the defendant actually completed a legal transgression. Mens rea, or 'guilty mind,' refers to whether the defendant intentionally committed a crime, which is usually synonymous with whether that crime was premeditated. In the legal setting, premeditation suggests that the defendant both foresaw the consequences of her action and had sufficient personal control to have prevented the criminal act if she so desired. Although a defendant may 
still be held accountable for an unintended guilty action, judging that a crime was premeditated dramatically increases ascriptions of blame and punishment. For example, murder and manslaughter are both convictions for the same action (i.e., killing a person), but the differences in attributions of intention result in markedly different sentences: The recommended sentence for first-degree murder (i.e., a premeditated killing) is life in prison, whereas the sentence for voluntary manslaughter (i.e., an unpremeditated killing) is 10 years in prison (United States Sentencing Commission, 2004). The difference in punishment for these otherwise similar crimes highlights the importance society ascribes to premeditation when determining whether actions were under personal control.

Despite frequently making premeditated decisions and making inferences about which decisions made by other people were premeditated, we know little about what premeditation specifically entails. We may recognize at an intuitive level when an action is premeditated (killing your boss after hours of thought), or not premeditated (reflexively kicking your leg when the doctor taps your knee), but what must occur for something to be premeditated? One obvious criterion is that you have to think about something in advance for it to be a premeditated outcome, but will any thought do, or must the kind of thought we engage in or its content be more specific? This chapter examines the nature of premeditation-how it is perceived and whether it is a reliable indicator of self-control. We explore the five requirements for an outcome to look and feel like it was produced by a premeditated decision, and investigate the efficacy of premeditation. As phenomenal experience and the law suggest, premeditation may equally influence both our feelings of control and actual control over our actions and the outcomes they produce (illustrated in the top half of Figure 1). 
Alternatively, in spite of the importance placed upon premeditation, it may often be purely incidental cognition. In other words, premeditation may fail to influence our judgment, even when we feel certain that it determined the outcome we chose. Like superstitious fans who believe they can influence the outcome of a football game by crossing their fingers or wearing the jersey of their favorite player, when premeditating we may sometimes be ritualistically engaging in an ineffectual behavior. We suggest that although premeditation may increase feelings of self-control, it may not serve as a reliable indicator of whether we actually possessed control over an outcome. Conscious thought may often only be tenuously linked to our actual behavior, and in such situations, the presence of premeditation may trick us to feeling like we controlled an outcome (as illustrated by the bottom half of Figure 1). Consequently, if premeditation leads to the experience of self-control without providing authentic control, then the increased guilt and self-loathing we experience after succumbing to temptations we consciously tried to resist may be largely unwarranted.

\section{ACTORS’ PERCEPTIONS}

Each of us has experienced what it feels like to have successfully made a decisionwe desired some outcome and persevered until it was produced. We also know what it feels like to have done something without thinking about it in advance or consciously making a decision (“how did I end up with this bowl of chocolate pudding and a ladle?”). What distinguishes between such "premeditated" decisions and "unmeditated" behavior-what leads us to feel that outcomes were intentionally chosen or unintentionally produced? Drawing from Apparent Mental Causation theory (Wegner, 2002; 2003; Wegner \& Wheatley, 1999) and Rational Choice theory (e.g., von Neumann 
\& Morgenstern, 1944), we suggest that there are five basic requirements that reflect the general structure of premeditated decisions.

Premeditated decisions begin with the identification of a problem or an unfulfilled goal, whether minor (“What should I eat for lunch?”) or major (“Should I have surgery or try physical therapy?”). Once a problem or goal has been identified, information is gathered about the alternatives that are available ("Peanut butter and jelly again or pizza?”) and each alternative’s positive and negative consequences. After identifying an alternative as satisfactory or the best available (Schwartz et al., 2002; Simon, 1957), controlled effort is applied in an attempt to bring about the outcome one desires (e.g., spreading preserves, putting a plate in the microwave, or consulting a second physician). Whether evaluating the choice of a meal or medical procedure, we may thus consider the fulfillment of five criteria to determine if an outcome was premeditated. Premeditation appears to be thought that (1) is used to identify a preferred option from a set consisting of multiple alternatives, (2) occurs prior to the outcome produced, (3) is consistent with the outcome produced, (4) is exclusively related to the outcome, and (5) leads to the application of effort to bring about the outcome.

Although thought that fulfills each of these criteria will lead us to feel that an outcome was premeditated and under our control, all of these need not necessarily be fulfilled for us to feel that we are in control. Rather than a strict checklist, these factors appear to represent a set of rough guidelines. The presence of some of these factors in situations where we have no control over outcomes may erroneously suggest that we possessed control over an outcome that we did not. In other words, purely incidental 
thoughts may lead us to experience the feeling of control, and thus fool us into believing those outcomes were produced by our premeditation.

\section{Requirement 1: Multiple potential courses of action}

The first guideline indicating that an outcome was premeditated and under our control is the existence of multiple alternatives, whether they are real or illusory. This can include having considered two or more alternatives, having considered whether or not to produce a single outcome, or having the potential to have considered alternatives. When deciding what to eat for dinner, for example, leftover pizza from the department lunch may be the only food left in your refrigerator. You may have eaten it $99 \%$ of the time in similar past instances, but you may still feel like you have control over your dinner selection because you know that you could order takeout from a neighborhood restaurant. You may be just as likely to eat the leftover pizza at home as you would be if captors gave it to you while in solitary confinement, but in the former case you would attribute your pizza-eating to your decision, whereas the lack of alternatives in solitary confinement (among other factors) would make you feel little control over the contents of your dinner. In many cases we may thus select the option that is dominant as dictated by our habits or culture (e.g., to leave a tip), but only perceive that option to have been intentionally chosen if we also considered its alternatives (Fiske, 1989).

The availability of multiple possible outcomes may be a legitimate requirement for a premeditated decision, yet there are instances in which alternatives to the outcome produced were not realistic or feasible and still their presence makes us feel like we were in control. One outcome may be so preferable that its alternatives would never be selected (e.g., “Hmm... looks like leftover pizza or dog food.” and "Honey, would you 
prefer to watch Dr. Strangelove or a documentary about root canals tonight?”). Desirable alternatives may exist, but may not be feasible economically ("Should we buy the Ford or the Maserati?”), socially (“Should we have beef brisket or eat the neighbors?”), or temporally (“Sorry, we just ran out of the scallops.”). And we may only realize that alternatives existed after an outcome was selected ("They had chocolate and strawberry?"). In short, there are a host of situations in life where actors may erroneously believe that alternatives were available at the time of a decision.

Conversely, we often feel no control over our premeditated decisions when alternatives to the course of action we select are ignored. Deciding not to act or simply discontinuing a current course of action (i.e., maintaining the status quo), are often not perceived to be decisions. Avoiding or delaying a decision, or asking someone else to make a decision for us, are also not usually perceived to be decisions (Anderson, 2003). Perhaps this is why we generally consider ourselves and others less responsible for outcomes that result from a decision not to act (i.e., acts of omission) than for identical outcomes produced by an action (i.e., acts of commission; Spranca, Minsk, \& Baron, 1991).

As we believe that a decision was premeditated when alternatives to the chosen outcome were unfeasible and that no decision was made when non-obvious alternatives were present, the mere presence of alternatives may engender the feeling that one has control over an outcome-whether we could have chosen those alternatives or not. A series of art selection experiments (Morewedge \& Wegner, 2008) explored this possibility by testing whether we are more likely to consider outcomes to be under our 
control when alternatives outcomes are present at the time of selection, but cannot actually be selected.

Participants randomly "selected” one of two works of art to see for 20s on each trial in a thirty trial experiment by pressing a key on the right or left of their keyboard. The term "selected” is used because participants had no real control-there was no consistent relation between the button they pushed and the artwork they saw. Sometimes the right and left keys corresponded to the work on the right and left, respectively. Other times those keys corresponded to the works on the left and right, respectively. Thus, in a sense they were randomly hitting keys, and the computer was randomly presenting photographs and paintings. Importantly, participants were informed of the lack of consistent correspondence between the keys and artworks at the beginning of the experiment.

Before randomly selecting a photograph or painting, participants saw small thumbnail-sized previews of both, one, or none of the artworks they could see in that trial (see Figure 1). At the end of each trial, participants reported the extent to which they felt they controlled the outcome of the selection, and whether the artwork selected was the artwork they intended to see. These reports were averaged to create an index of participants’ perceived control over the selection of outcomes. Although people often claim to control outcomes that are purely random (Langer, 1975), notice that these selections were equally random, regardless of the number of previews participants saw in the beginning of each trial.

If participants reported feeling more control over the selection of artwork in trials when they saw more rather than fewer previews, it would appear that participants used the mere presence of alternatives to infer the extent to which they controlled the artwork 
selected. They did just that. Participants were more likely to report feeling control over the works selected when both of the artworks were previewed than when only one work was previewed. And they were more likely to report feeling control over works selected when only one work was previewed than when neither work was previewed-even when the work previewed was inconsistent with the work selected. In short, the greater the number of previews seen before a selection was displayed, the more control participants felt over the selection, whether or not the preview matched the randomly selected outcome (Morewedge \& Wegner, 2008, Experiment 1).

A second experiment assessed both sensitivity to the number of alternatives previewed and the extent to which participants could actually control the selection (Morewedge \& Wegner, 2008, Experiment 2). Using a similar procedure, participants saw two, one, or no previews of the works of art they could see in each trial of a thirty trial experiment (within-subjects). In this experiment, however, the extent to which participants could control the selection was varied between-subjects: Participants in a complete control condition could control the painting they selected (the left and right keys consistently referred to the left and right artworks on all trials). Participants in a random control condition randomly selected paintings as described in the previous experiment, and participants in a no control condition simply pressed a spacebar to have the computer program randomly select a painting for them.

If participants were simply confused about the extent to which they controlled the selection process in the previous experiment, we would expect that those in the complete control and random control conditions would report similar feelings of control, but both groups would report feeling more control than participants in the no control condition 
(whose lack of control should be fairly clear). Participants did not appear to be confused, as they were sensitive to the amount of actual control they possessed in the experiment. Those with complete control reported feeling greater control than participants with random control condition, and both groups of participants reported feeling more control than participants with no control.

As in the first experiment, those in the complete control and random control conditions reported feeling more control over selections when they saw more rather than fewer previews. Interestingly, participants in the no control condition reported feeling no more control over outcomes whether they were presented with more or fewer previews. This suggests that the appearance of alternative courses of action is necessary for one to feel that an outcome was the result of a premeditated decision-it is not enough to simply see alternative potential outcomes.

The results of these two experiments suggest that the mere presence of alternatives make actors feel like they made a premeditated decision. It is important to note that the results suggest it is the perception of possible alternatives that influences judgments of control, independent of a person's actual ability to control the alternative selected. What follows is an examination of additional criteria that serve as indicators of premeditation and control, and whether actors are sensitive to the fact that those criteria were actually met or only note whether those criteria were apparently fulfilled.

\section{Requirement 2: Priority}

A second requirement for an outcome to appear to have resulted from premeditation is for it to have been considered before the action producing it was executed. Thinking about options after executing the critical action can hardly be considered a decision, since 
that thought could have had no causal impact on the action or its consequences (c.f., Radin, 2006). This priority principal is perhaps best demonstrated by an experiment (Wegner \& Wheatley, 1999) in which each participant and a confederate placed their hands upon a disk similar to a planchette — a heart shaped object used to spell out messages and select responses on a Ouija board - to move a computer mouse beneath the disk across a computer display. The display consisted of objects such as a house, duck, and rowboat. The participant and confederate moved the disk together to select an object while listening to audio tracks (played over headphones). Unbeknownst to participants, on critical trials a certain object was preselected, and the confederate subtly pushed the planchette so that it rested upon the preselected object. On these critical trials, the participants would hear the name of the preselected object over the headphone. In the experiment, whether the participant heard the name of the preselected object before or after the selection was varied within subjects. Participants reported feeling more control over the selection of the object if it was named before than after the selection. In other words, only thoughts occurring prior to an outcome were perceived to produce it.

Perhaps prior knowledge of our alternatives is also crucial for an outcome to be considered the result of one's premeditated decision. Another art selection experiment examined this possibility. Participants in a prior knowledge condition and a delayed knowledge condition randomly selected works of art to see in a paradigm similar to the first art selection experiment. In the prior knowledge condition, participants saw two, one, or no thumbnail previews of works of art before they randomly selected a work to see for 20s. In the delayed knowledge condition, participants saw two, one, or no thumbnail post-views of works of art after they randomly selected a work, but before 
they saw the work they selected. Thus, both groups of participants received the same information about the options available in each trial, but only those in the prior knowledge condition knew of options before making a selection.

As in the other experiment (where all participants had prior knowledge), participants in the prior knowledge condition reported feeling more control over their selection when they saw more rather than fewer previews. Participants in the delayed knowledge condition, however, reported feeling equivalent control over selections irrespective of the number of post-views they saw in trials (and reported feeling less control than participants in the prior knowledge condition). Although participants in prior and delayed knowledge conditions had the same amount of control over the works of art selected in this experiment and saw the same number of pre- and post-views, only participants who saw the alternatives in advance felt like the outcome was the result of their decision. In other words, even though all works were randomly selected, participants felt control over selections only when the priority requirement was fulfilled. Thus, people appear to consider outcomes to be result of their decisions only when their alternatives were considered beforehand, even when that consideration was purely incidental to the outcome produced.

\section{Requirement 3: Consistency}

For an outcome to be considered the product of a premeditated decision, it must presumably be consistent with the thoughts preceding it. If we've thought about eating a hamburger all day and find turkey on our dinner plate, we may question how it got there. We expect outcomes to conform to our thoughts, and use the consistency between the two to determine which outcomes we controlled. In a laboratory setting, people examine 
their thoughts just before an outcome to determine if they consciously willed it (Wegner, 2002; 2003). In a legal domain, people examine the thoughts of defendants to assess how much punishment they deserve for the crime they committed. If a killer said, "I thought about how I could kill Roger with a blow to the head,” she would presumably be locked away for a long time. On the other hand, if she said, "I thought about how I could hit a nail and discovered that I had Roger instead,” the inconsistency between her thought and the outcome suggests that she didn't plan to kill Roger or control the action that did (Hart \& Honoré, 1959/2002).

Even when outcomes are produced by chance, consistency between intention and outcome may give rise to the feeling of personal control. The repeated production of intended events—such as successfully flipping a coin so it turns up heads five times in a row-may give rise to the feeling that we controlled those events through skilled action rather than chance (Langer, 1975; 1983; Langer \& Roth, 1975). One implication of the consistency requirement is that people should take more credit for their triumphs (which they are likely to imagine) than their failures (which they would prefer to ignore), a tendency that has been demonstrated to be robust (for a review, see Miller \& Ross, 1975). Indeed, this tendency is so robust that people even take credit for the outcomes they merely intended to produce. People praise themselves for simply intending to help the needy, for example, whether or not they actually did (Kruger \& Gilovich, 2004). Depressed individuals appear to be one of the few exceptions to this pervasive tendency (Alloy \& Abramson, 1979), as they less often over-claim responsibility for their successes than do non-depressed individuals. 
Not only can the consistency principle lead us to feel control over the things we didn't cause, it can lead even those of us who are sane to believe we possess supernatural powers. In one study, participants were asked to stick pins into the head of a voodoo doll made to resemble a partner-another participant who was actually a confederate of the experimenter. Participants were more likely to report feeling personally responsible for their partner experiencing the sudden onset of a headache if they were previously led to dislike their partner (i.e., when their partner showed up late to the study wearing a trucker hat emblazoned with the motto, “Stupid People Shouldn’t Breed”), than if they were not previously led to dislike their partner (i.e., when their partner showed up on time and was dressed inoffensively; Pronin, Wegner, McCarthy, \& Rodriguez, 2006).

It seems that thoughts only need to appear consistent with outcomes for us to claim those outcomes were intentionally produced. Indeed, decision makers can even be led to believe they chose an option they actually rejected. Such choice blindness is typically produced by having participants pick between two similar alternatives and then seeing if participants can be tricked into believing they selected the unchosen alternative. In one demonstration, men were shown pairs of cards depicting similar women and were asked to choose which was more attractive (Johansson, Hall, Sikstrom, \& Olsson, 2005). On each trial, participants were asked to explain why they preferred the woman they chose. On choice blindness trials, the experimenter (who was a magician) used sleight of hand to switch the cards and showed each man his unchosen alternative-acting as if he had preferred the woman he said was less attractive. Thirty percent of the men completely missed the switch! Even more surprising was their readiness to give reasons for having “chosen” the woman they had actually rejected, "She’s radiant. I would rather 
have approached her at a bar than the other one” (Johansson et al., 2006, p.118).

Participants apparently forgot which woman they chose, and inferred from the similarity between their choice and the outcome that they preferred the less attractive woman.

Indeed, in hindsight we overestimate the consistency between our original intentions and the outcomes of our decisions (Pieters, Baumgartner, \& Bagozzi, 2006).

Sometimes rather than forgetting which option we choose, we entirely forget all of our options. Chance and Norton (2007) showed research participants pairs of colors and asked them to identify which color they preferred in each pair. Although the behavior of participants demonstrated they had seen the color pairs before- they performed above chance when later distinguishing between old and new pairs—on average participants falsely reported having never seen $25 \%$ of the original color pairs. Interestingly, participants were especially likely to forget the original color pairs that were most difficult to choose from.

People may forget which alternatives they originally chose or were available, but there are likely to be limits to their forgetfulness. With an art selection experiment, we investigated the extent to which participants used false feelings of consistency to infer that they made a decision. Using a paradigm similar to the previously described art selection experiments, participants randomly selected one of two works of art to see by pressing one of two keys after seeing two, one, or no previews of the works. In this experiment, however, previews could either be accurate previews of the works of art (as before), inaccurate previews of the works of art, or accurate previews of the works of art that were distorted beyond recognition (see Figure 2). 
As in previous experiments, participants felt more control when they saw a larger number of accurate previews. More important, feelings of control were not affected by the number of inaccurate and distorted previews that participants saw (Morewedge \& Wegner, 2008, Experiment 4). In other words, when the previews represented possible outcomes, participants felt more responsible with more previews, but when previews provided information that was irrelevant or uninformative, feelings of responsibility were unrelated to the number of previews they saw. It appears that outcomes need not be consistent with the most preferred choice. Rather, the outcome of a decision must be consistent with at least some of the possible alternatives. These findings suggest that when examining the consistency between our intentions and outcomes, we reconstruct rather than recall the outcome we originally intended to produce.

\section{Requirement 4: Exclusivity}

For an outcome to feel like the result of a premeditated decision, it must appear to have been produced exclusively by one’s intentions. If Bobby’s mother tells him to eat his peas and Bobby decides to eat them, who gets credit for the pea-eating? Most likely, Bobby's mother. Whether situational constraints are strong or subtle, we are quick to deny responsibility for undesirable outcomes produced by our behavior when it can be attributed to external influences. Obedience experiments by Milgram (1974) demonstrate that the perception of responsibility for nefarious outcomes-outcomes endangering the life of another human being - may be abnegated when we receive direction from an authority figure. The suggestions of an authority led teachers in Milgram’s experiments to believe that they were forced to rather than decided to expose a learner to levels of 
electric shock that could prove fatal, even though teachers had full control over the fate of learners and had the option to disobey the authority figure.

Like the other requirements for premeditation, it appears that perceived rather than actual exclusivity is crucial when determining personal control over outcomes. We can be easily led to ignore real exclusivity: Cognitive dissonance experiments show that we are quick to attribute the discomfort arising from our decisions to placebos such as a sugar pill (Harmon-Jones \& Mills, 1999; Zanna \& Cooper, 1974). Conversely, we sometimes claim exclusivity for outcomes caused by external forces. For example, we take full responsibility for and generate reasons why we produced actions that were performed because they were suggested by a hypnotist (Wheatley \& Haidt, 2005), or why we made decisions that were due to irrelevant contextual influences such as the order in which options were presented (Nisbett \& Wilson, 1977).

The tendency to confuse exclusivity has important implications, as in the case of facilitated communication — a technique in which a facilitator (usually a therapist) lays their hands atop the hands of a patient (e.g., an autistic child), and interprets their slight movements as meaningful responses to questions posed to the patient. While it sounds like a good idea in theory, in practice facilitators answer the questions themselves and attribute their answers to the patients (Wegner, Fuller, \& Sparrow, 2003).

Requirement 5: Effort

Once an outcome has been chosen, the translation of that thought into action requires controlled effort (James, 1890/1955), which appears to be the final requirement for an outcome to be perceived as premeditated. As a result, outcomes chosen out of habit or 
that are easy to perform in a given situation are less likely to be perceived to be under our control than actions that are unusual or difficult (Fiske, 1989).

Perhaps this is because effort is usually exerted during the process of decisionmaking, as evidenced by a decreased ability to perform effortful tasks after having made a decision. Like the performance of tasks requiring self-control, making judgments and decisions appears to deplete a limited resource that some have suggested is will-power (Masicampo \& Baumeister, 2008; Vohs \& Faber, 2007). In perhaps the best illustration, participants were placed in a room for five minutes with a plate of freshly baked chocolate chip cookies and a plate of radishes. Participants instructed to eat only radishes quit attempting a subsequent (impossible) line tracing task more quickly than controls and participants who were instructed to eat only the cookies (Baumeister, Bratslavsky, Muraven, \& Tice, 1998). Presumably, suppressing one’s desire to eat the cookies taxed participants' ability to persist in the subsequent task.

Expending effort while an outcome is produced, however, may mistakenly lead us to feel responsible for producing it. For example, a Eureka error is particularly likely when we expend more mental or physical effort during the generation of a solution than during the presentation of a solution. In one study, participants were paired with a partner and asked to solve anagrams together (Preston \& Wegner, 2007). When participants were asked to squeeze a handgrip while thinking of solutions, they claimed credit for the solution, regardless of whether they or their partner solved it. Similar effects were found in other experiments when anagrams required extensive effort to read because they were presented in a barely legible font. Participants were more likely to falsely claim credit for solutions to anagrams when the anagrams were displayed in the difficult to read font than 
an easier to read font. Participants were thus likely to feel responsible for an outcome when they engaged in effortful thinking during its production.

Indeed, merely engaging in effortful thinking about anything before producing an outcome may lead us to claim more control over that outcome, even when it was randomly produced. In another art selection task, participants saw thumbnail previews of the two works of art that could be selected in each trial. On two-thirds of trials, participants performed one of two other tasks before selecting a painting. Half of the time, participants answered a relevant question—what they were thinking and feeling at the time. Half of the time, participants answered irrelevant questions such as, "What word do you associate with tube socks?” and "What's a fair price for a banana cream pie?”

Although participants reported more control over trials in which they performed an additional task, the results of this study indicate that the content of the task did not matter. Relative to no-task trials, participants reported feeling greater, but equal amounts of control over the trials in which they answered relevant and irrelevant questions. So regardless of whether their thoughts were relevant to the task at hand, participants felt more control over outcomes after having thought about something—anything—before the outcome was produced (Morewedge \& Wegner, 2008, Experiment 5).

\section{Summary}

These five sections outline the necessary components of premeditation, which give rise to the experience of control over the outcomes of decisions, and suggest that their presence often fools us into believing we determined them. Multiple alternatives need merely be present, not possible, to make outcomes feel like the product of our decisions. These alternatives must appear in advance of the decision, regardless of 
whether they can actually be chosen, to make the outcome feel like it was under our control. Even when we have no real choice, we feel that we determined outcomes when they appear consistent with our intentions and free of external influence. Finally, any kind of thinking before a decision, whether related or not, appears to lead to the perception that an outcome was the result of a premeditated decision-that our thoughts and actions corresponding to those thoughts controlled it. Although premeditation may indicate that we considered our options before making a decision, we appear to have difficulty determining when it did not lead to the production of the outcomes we intended and when it did.

\section{OBSERVERS’ PERCEPTIONS}

When determining whether an outcome was the result of a premeditated decision, actors have the privilege of knowing the thoughts and alternatives they considered prior to its production. Observers have a more difficult task, as they must infer which thoughts and alternatives were considered by actors prior to the production of outcomes. Although an enormous body of research suggests that actors and observers differ in the way they ultimately attribute responsibility for outcomes (Gilbert \& Malone, 1995; Jones \& Harris, 1967; Kelley, 1973; Ross \& Nisbett, 1991), observers who believe they possess knowledge of the prior thoughts and alternatives available to actors judge premeditation according to criteria similar to the criteria that actors use. Observers examine whether actors had multiple options to consider or chose from, could have foreseen and desired to produce the outcome, whether actors' intentions appeared to be the sole cause of the outcome, and the effort actors expended toward creating the outcome produced (Pizarro, Uhlmann, \& Bloom, 2003; Shaver, 1985; Weiner, 1995). Like actors, however, observers 
may merely examine whether these requirements appear to have been satisfied. Observers who do not believe they possess such knowledge judge premeditation by making more general inferences about the actor and the apparent goal of the outcome produced. In both cases, however, these judgments are made under uncertainty. Observers’ judgments may thus depend largely upon superficial fulfillment of the criteria for a decision to be premeditated, and substitute their own intuitions and emotions for evidence when none is available (Haidt, 2001; Kahneman \& Frederick, 2002; Kahneman, Schkade, \& Sunstein, 1998).

Furthermore, observers may be motivated to infer that these requirements have been satisfied to validate their feelings and intuitions that someone should be praised or blamed for the outcome (Alicke, 2000; Haidt, 2001; Kahneman, Schakde, \& Sunstein, 1998). Indeed, such intuitions are unlikely to be corrected, as people generally believe their judgments are veridical assessments of the world (Nisbett \& Wilson, 1977; Pronin, Gilovich \& Ross, 2004). Although observers may examine whether actions meet the five requirements actors use to assess premeditation, observers' examination of these requirements is often cursory, merely a ritual used to justify the ascription of causal responsibility and hence praise or blame.

\section{Requirement 1: Multiple potential courses of action}

Observers are most likely to consider an outcome the result of a premeditated decision and thus under actors’ control when actors appear to have had multiple alternatives available to them. In some way, observers are more likely than actors to believe that alternatives were possible, as they tend to perceive that actors could have produced an alternative outcome even when actors were unaware that alternative existed. 
Wells and Gavanski (1989), for example, asked people to assess an employer’s responsibility for indirectly killing his employee by ordering an entrée containing an ingredient to which she was highly allergic. In one version of the scenario, the employer selected between two entrees for the employee, both containing the lethal ingredient. In the other version, only one of the two entrées contained the lethal ingredient. Although the employer was unaware of her allergy in both scenarios, he was seen as having greater control over her life and death when only one entrée was fatal than when both were fatal. Of course, the employer had no real control over her fate in either scenario-in both cases he did not know that either entrée would kill his employee. Yet, observers inferred that because the employer could have chosen a non-fatal entrée, the employer was more responsible for choosing an entrée that killed her.

\section{Requirement 2: Priority}

Retrospectively discerning whether outcomes were foreseeable at the time of judgment is a challenging task for observers. A curse of knowledge-knowing with certainty the events that occurred-hinders observers’ ability to imagine actors' thoughts when faced with a decision (Camerer, Loewenstein, \& Weber, 1989). Knowledgeable observers may have difficulty conceiving of a situation in which actors were not aware of the all of the consequences of the outcome chosen. Children have particular difficulty accounting for knowledge that they possess when predicting naïve actors’ behavior (Wimmer \& Perner, 1983). Although adults are influenced to a lesser degree by prior knowledge than children, adults appear to be better at correcting for the knowledge they possess rather than be less likely to initially exhibit egocentrism (Epley, Morewedge, \& Keysar, 2004). The certainty hindsight provides also makes the foreseeability of an 
outcome seem greater, leading even experts to overestimate the probability of events (Fischhoff, 1975). It is thus not only difficult for observers to be able to discern actors’ thoughts at the time of judgment, knowledge of the outcomes of actions bias observers' judgments so that they are likely to believe actors knew and desired to bring about the outcomes produced.

\section{Requirement 3: Consistency}

Consistency between an actor's prior thoughts or desires and an outcome lead observers to consider actions premeditated, whether or not the actor's thoughts and desires could influence the outcome. Woolfolk, Doris, and Darley (2006) showed that actors are held more culpable for actions they intended, even if their intentions were completely irrelevant to the production of the action. Observers read a vignette in which a protagonist was given a drug by terrorists that made him powerless to resist their command that he kill a man, and then judged how responsible the he was for that killing. Half of participants were informed that the protagonist had previously thought about killing the man and wanted him dead, whereas the other half were informed that the protagonist had never thought about killing the man and wanted him to live. In both cases, the protagonist had no control over the outcome he produced (the man's death), but observers ascribed more blame to the target when the outcome was consistent than inconsistent with his desires.

Consistency between the outcome that occurred and the outcome an actor intended to produce, however, does not appear to be sufficient for an act to be considered the result of a premeditated decision. Observers appear to be sensitive to the consistency between the action intended to produce an outcome and the action that actually produced 
it. A person intending to break into his uncle's house and kill him, for example, is considered less culpable for the death of his uncle if he accidentally ran into and killed the uncle while driving to the house, than if he killed his uncle in the house as he originally planned (Pizarro, Uleman, \& Bloom, 2003). Although the actor produced the outcome he desired - the death of his uncle-observers only considered the outcome to have been premeditated when the sequence of events producing his uncle's death were consistent with the sequence he planned to execute.

When observers are unsure of actors’ prior intentions, they may base judgments of premeditation on the consistency between outcomes and their lay theories of actors' general inclinations or meta-desires. For example, people are considered less blameworthy for moral transgressions that appear to have been committed impulsively than moral transgressions that appear to involve premeditation (“She doesn’t really dislike me—she only chewed me out because she was drunk”), because most people have a meta-desire to avoid doing bad. Conversely, people are not considered less praiseworthy for good behaviors committed impulsively than good behaviors that appear premeditated, because most people have a meta-desire to do good (Pizarro, Bloom, \& Salovey, 2003). Interestingly, this suggests that actors who are generally perceived to desire to do evil are not excused from impulsive immoral acts because those acts are considered consistent with their meta-desires.

Finally, observers occasionally engage in attribute substitution (Kahneman \& Frederick, 2002), overextending consistency to include unintended side-effects of the outcome produced. In the Wells and Gavanski (1989) case mentioned before, observers overextended the consistency between an employer's intention (i.e., to select an entrée 
for his employee) and action (i.e., ordering an entrée for his employee) to include an unintentional side-effect (i.e., his employee’s death). People are held similarly accountable by the law for unintended consequences of their actions, if the actions themselves were premeditated (Hart \& Honoré, 1959/2002). In a celebrated case, a man and an exotic dancer conspired to rob a rich client. The dancer entertained the client in his car until her accomplice opened the car door and pointed a gun at the client. Although her accomplice had no desire to shoot the client, he slipped on a patch of ice and pulled the trigger. The client was killed by the stray bullet and the accomplice was convicted of felony murder because he was engaging in an intentional illegal act (Alicke, 2000). Observers are especially likely to attribute unintended side effects to actors’ intentions when the outcome and original intention are similar. A person is considered more culpable for having caused a car accident while speeding, for example, if he was rushing home to hide a vial of cocaine than to hide an anniversary gift. In this case, criminal intentions to hide an illegal substance presumably were generalized to include any potentially harmful outcome (Alicke, 1992).

\section{Requirement 4: Exclusivity}

Under ordinary circumstances, for a variety of reasons, observers tend to assume that actors’ behavior was due to their intentions and dispositions (Gilbert \& Malone, 1995; Ichheiser, 1949; Jones \& Davis, 1965; Jones \& Harris, 1967; c.f., Krull, 1993). For instance, observers are generally less sensitive than actors to the presence of external influences when inferring what caused actors to behave and choose as they do. A seminal demonstration by Jones and Harris (1967) asked participants to read an essay supporting or opposing Fidel Castro’s governance of Cuba and then infer the essay writer's opinion. 
Some readers were told that writers were free to choose a position to endorse, whereas other readers were told that writers were assigned to endorse a position. Despite knowing that essay writers were forced support or oppose Castro in the latter condition, essay readers inferred that the writers' attitudes toward Castro were reflected by the position participants (unwillingly) espoused.

One notable exception to this correspondence bias is observers' tendency to attribute counterfactual blame (Miller, Visser, \& Staub, 2005). When the constraints of the situation are so severe that there are no possible alternative courses of action available, observers' dispositionalism is sometimes so strong that they assume actors' intentions were contrary to their behavior. Miller and colleagues (2005) showed a person taking a test with or without strict supervision to observers and then asked observers to assess the test taker's character. When the test taker was under strict supervision, observers considered her less trustworthy than when the test taker was under no supervision. Observers appear to have assumed that she would have cheated in the latter case if there were weaker situational constraints. A vice-principle at a high school with strict rules, for instance, may thus believe that students would run wild if restrictions were loosened and seek to enact even stricter regulations. In short, observers appear to consider exclusivity quite differently than do actors. They generally perceive actors to have controlled actions that were performed as a result of substantial coercion, and believe they can infer actors' intentions even when actors are forced to engage in specific behaviors. 
Requirement 5: Effort

Although observers often discount the influence of the situation in attributing responsibility, certain outcomes appear premeditated because of the substantial effort required to enact them. In any situation, there is usually a course of action that is normative, and when a counter-normative or unusual action is observed, it is thought to have been consciously chosen. For example, most people buy groceries at the supermarket, so learning that a person only purchases groceries from a farm co-op may lead you to believe that she really cares about where her broccoli comes from. Similarly, most people drive at or above the speed-limit, so we may infer that a person driving more slowly than the limit intends to do so, assuming we do not simply infer that the driver is incompetent (c.f., Morewedge, Preston, \& Wegner, 2007). Choosing such non-dominant alternatives is often called making the "hard choice” (Fiske, 1989), a term implying that the decision-maker was not only aware of the alternative, but possessed both the cognitive resources and sufficient control over her situation to reject the modal response (Gilbert, 1991; Shiv \& Fedorikhin, 1999).

\section{Summary}

Observers appear to evaluate the same requirements actors do when discerning whether an outcome was due to a premeditated decision, and like actors, they often evaluate those requirements in a cursory manner. Observers' inability to know actors' desires, whether alternatives were recognized or considered, and the difficulty of disentangling the person from the situation, leads observers to more often attribute premeditation of and control over outcomes to actors than actors attribute to themselves. This is exacerbated by observers' tendency to generalize actors' intention to produce an 
outcome to include the outcome's unforeseeable side-effects, and a failure to discount knowledge gained from hindsight.

\section{EFFECTS OF PREMEDITATION}

The evidence presented suggests that the presence of premeditation does not serve as a reliable index of personal control. If premeditation is present before outcomes that we did not cause and absent before outcomes that we did, it is questionable whether premeditation deserves to be considered an indicator of intentional action. In a broad sense, judgments and decisions are influenced by information that is cognitively available when they are made (Kahneman \& Frederick, 2002; Morewedge, Gilbert, \& Wilson, 2005; Tversky \& Kahneman, 1973; Winkielman \& Schwarz, 2001), so it would be surprising if information considered during premeditation had no effect on outcomes produced by the premeditator. Given the serious social and legal consequences of considering an outcome to have been caused by a premeditated decision (Denno, 2003; Federal Sentencing Guidelines, 2004; Kadish \& Schulhofer, 1995; Weiner, 1995), it is natural to wonder: What are the effects of premeditation on decision making?

It is clear that merely thinking about a desired action makes us more likely to produce it, particularly when that action is easy to imagine (Levav \& Fitzsimmons, 2006). Indeed, we are more likely to perform prosocial actions and less likely to perform antisocial actions if we think about them in advance (Sherman, 1980). Registered voters asked if they intended to vote in an election were $25 \%$ more likely to vote in that election than voters who were not asked (Greenwald, Carnot, Beach, \& Young, 1987). M.B.A. students led to think about flossing their teeth more frequently flossed than those led to think about reading for pleasure (Levav \& Fitzsimmons, 2006). Perhaps most surprising, 
participants in a nationally representative sample of more than 40,000 American households were $35 \%$ more likely to make a purchase costing thousands of dollars-a car-within six months of the survey if they were asked if they intended to buy one in the near or distant future (Morwitz, Johnson, \& Schmittlien, 1993).

One way premeditation may affect the production of an outcome is through the formation of implementation intentions, which cue goal-directed responses when presented with specific situations (Gollwitzer, 1999). For example, you may wish to finish some home renovations by the end of the week, and thus plan to decline the after work invitations of your colleagues so you can go home early to renovate. By deciding beforehand how to respond when a relevant situation presents itself, you can work towards your goals and avoid getting sidelined by distractions and procrastination (Dellarosa \& Bourne, 1984). Furthermore, preemptively deciding how to behave may lead to the eventual automatization of the intended goal-directed behavior (Bargh, 1997; Gollwitzer, 1993; 1996).

Although premeditation can help us work towards goals by increasing the probability that an intended outcome will be produced, the effects of premeditation are not always beneficial. Wilson and Schooler (1991) found that novice jam-tasters asked to rate jams after introspecting about their opinions were less accurate in their taste ratings than novice jam-tasters in a control condition. Similarly, students who introspected about their artistic preferences before choosing one of two posters to adorn their dorm room were less likely than controls to choose a high-quality art poster rather than a lowerquality humorous poster (e.g., Starry Night by Van Gogh rather than Garfield by Jim Davis). Furthermore, those introspectors reported feeling less satisfied with their decision 
three weeks later than did controls, suggesting that premeditation can impair the stability of preferences used to inform judgments and decisions (Wilson, Lisle, Schooler, Hodges, Klaaren, \& LaFleur, 1993).

Dijksterhuis (2004) examined effect of premeditation on the quality of decisions and found its usefulness depends on the complexity of the decision and the kind of deliberation used to make it. He suggests that conscious deliberation improves the quality of simple decisions such as which shampoo or which oven mitts to buy, as it is possible to simultaneously compare a few dimensions or features consciously. Dijksterhuis also suggests, however, that conscious deliberation reduces the quality of complex decisions such as which person to marry or which house to buy, because we cannot simultaneously compare a large number of dimensions or features consciously. Instead, we end up overweighting the few features or dimensions we can consider and underweighting unconsidered features when making complex decisions.

To test this detrimental effect of conscious deliberation, he asked participants to choose the best apartment out of a set of four, which varied across 12 attributes (e.g., amount of sunlight, attractiveness of the location, size). One apartment was clearly better than the other three because it possessed more positive and fewer negative attributes, although the descriptions were complex enough that comparing between apartments was difficult. Once all of the features of the apartments had been presented, participants indicated the apartment they preferred either (a) immediately (b) after consciously deliberating about the choice for five minutes, or (c) after performing an unrelated task for five minutes. Conscious deliberation did not improve the quality of decisions, as participants who spent five minutes deliberating before choosing were as likely to choose 
the best apartment as participants who chose immediately. More important, participants who performed an unrelated task for five minutes before choosing were most likely to pick the best apartment, a finding Dijksterhuis and colleagues (2005; Dijksterhuis \& Nordgen, 2006) attribute to the superiority of unconscious deliberation. They propose that unconscious deliberation possesses a greater capacity to simultaneously compare complex multidimensional stimuli and more accurately weight their attributes when making judgments and decisions.

In sum, the effects of premeditation appear to depend on the decision at hand. Premeditation increases the likelihood that actors will produce the premeditated outcomes and desired goal-directed behavior, which can be good or bad (e.g., committing one’s life to justice vs. committing murder). Whether premeditation improves or impairs decisions appears to depend on the alternatives considered. Premeditation appears to improve the quality of decisions involving alternatives that are relatively simple, but impairs the quality of decisions involving alternatives that are more complex.

\section{IMPLICATIONS FOR SELF-CONTROL}

The findings presented in this chapter suggest that premeditation may not reliably indicate when we possess control over a decision or outcome. Disturbingly, these findings not only imply that premeditation may not deserve the importance afforded it by society and the law, but also that we should reconsider and carefully examine the extent to which our conscious thoughts actually enable us ú $\quad$ xert self-control. If the link between premeditation and control is specious for unimportant decisions (like art selection), it is possible that conscious forethought also has little influence on more important decisions, such as those made when we are confronted with the choice to 
consume or abstain from the consumption of unhealthy foods, alcohol, cigarettes, and drugs. We may lament “Why didn’t I think this through?” after succumbing to temptation, but it may be that even with significant premeditation we would have awoken to find our shirts covered in powdered sugar and donut crumbs, our breath reeking of whisky, the only difference being the greater sting of guilt caused by the consideration our gluttonous behavior before we engaged in it.

We are considered more praiseworthy and blameworthy for actions when we considered the alternative courses of action available beforehand (Wells \& Gavanski, 1989), yet it is possible that the internal debate we engage in between resisting and giving in to temptation is often just for show. Indeed, much of our behavior is affected by unconscious goals and motivations (Dijksterhuis, Chartrand, \& Aarts, 2007; Förester, Liberman, \& Friedman, 2007). When we give into our temptation to eat that extra cookie, having thought about it in advance may do little other than make us feel guiltier because of it. On the other hand, when we are able to resist our impulses and make the appropriate choice, having consciously rebuffed temptation may make us feel empowered. The experience of conscious conflict may have the additional benefit of making us more satisfied with our choice to behave well (Brehm, 1956; Festinger, 1957).

We are not, however, advocating the embrace of the belief that we are all selfindulgent automatons, powerless to avoid our impulses to eat fattening foods and wash them down with stiff drinks, particularly as advocating such a belief may have profoundly negative consequences (Vohs \& Schooler, 2008). Rather, evidence suggests that the conscious struggle we engage in when faced with self-control dilemmas does actually have some influence over our behavior. We appear to have a limited resource of 
self-control which we can allocate toward specific tasks (Baumeister et al., 1998;

Wegner, 1994). The key puzzle appears to be determining what role conscious thought plays in the theater of self-control. Perhaps conscious thought determines the impulses that we should regulate with this limited resource and the impulses that are not worth attempting to control. We may thus decide to apply our limited resource of self-control to the dilemmas we consider most important, or to prevent the lapses that would reflect most poorly upon ourselves, just as people are able to selectively inhibit the forms of prejudice that are frowned upon by their society (Franco \& Maass, 1999). Alternatively, conscious thought may allow us to create automatic behavioral scripts-implementation intentions - that are carried out when we must exert self-control (Gollwitzer, 1999). Ironically, premeditation may influence decisions indirectly by automatizing the behaviors we consciously intend to produce.

\section{CONCLUSION}

Actors, observers, society, and the law place faith in premeditation as a principle indicator of personal control. The findings presented in this chapter illustrate many instances in which these faith-based judgments are misleading and often completely wrong. Actors have difficulty discerning the efficacy of their premeditation, and rely on the apparent rather than the actual fulfillment of the five criteria we reviewed: (1) having considered or the ability or consider multiple alternatives, (2) if the meditation they engaged in occurred prior to the action or outcome produced, (3) if outcomes were consistent with the alternatives they considered, (4) if outcomes were exclusively due to internal causation on the part of the actor, and (5) if outcomes occurred as a result of the actor's controlled effort. 
Observers more superficially assess the fulfillment of these five requirements to determine whether outcomes were caused by an actor's premeditation, and exhibit a general tendency to over-attribute outcomes to actors’ premeditated decisions. The cursory examination of alternatives, priority, consistency, exclusivity, and effort by observers is largely due to their lack of first hand knowledge, which is often inferred from their own intuitions, emotions, and beliefs about actors’ meta-desires.

Although premeditation increases the likelihood that we will produce the outcome we intend to perform, its benefits are questionable. Only relatively simple decisions appear to be improved, whereas its presence prior to complex decisions appears to impair them. Given the serious nature of its social and legal consequences, it may thus be time to reexamine the privileged position of this often ineffectual behavior. Premeditation appears to often be no more than ritual; incidental cognition that engenders false feelings of personal control. In spite of this, there may be hope for self-control if we can premeditate far enough in advance to form automatic action plans. Nevertheless, these findings suggest it may be time to seriously question whether premeditation deserves the importance granted to it by society and the law, and whether it should continue to serve as a primary indicator of personal control. 


\section{FOOTNOTE}

1. In this chapter, the terms premeditation, deliberation, and making decisions are distinct. We define premeditation as conscious thought corresponding to the performance of an action or decision before it is produced or determined. We define deliberation as conscious or unconscious consideration of a stimulus, potential action, etc., that may occur before, during, or after the performance of an action or decision. We define making decisions as the process of selecting a course of action to pursue or stimulus when faced with multiple alternatives, whether those alternatives are multiple courses of action and stimuli, or those alternatives involve either selecting an action or stimulus or not selecting that particular action or stimulus. 


\section{REFERENCES}

Alicke, M. D. (1992). Culpable causation. Journal of Personality and Social Psychology, 63(3), 368-378.

Alicke, M. D. (2000). Culpable control and the psychology of blame. Psychological Bulletin, 126(4), 556-574.

Alloy, L. B., \& Abramson, L. Y. (1979). Judgment of contingency in depressed and nondepressed students: sadder but wiser? Journal of Experimental Psychology: General, 108, 441-485.

Anderson, C. J. (2003). The psychology of doing nothing: Forms of decision avoidance result from reason and emotion. Psychological Bulletin, 129, 139-167.

Baumeister, R. F., Bratslavsky, E. Muraven, M., \& Tice, D. M. (1998). Ego depletion: Is the active self a limited resource? Journal of Personality and Social Psychology, 74, 1252-65.

Baumeister, R. F., \& Heatherton, T. F. (1996). Self-Regulation Failure: An Overview. Psychological Inquiry, 7, 1-15.

Bem, D. J., \& McConnell, H. K. Testing the self-perception explanation of dissonance phenomena: On the salience of premanipulation attitudes. Journal of Personality and Social Psychology, 14, 23-31.

Brehm, J.W. (1956). Postdecision changes in the desirability of alternatives. Journal of Abnormal and Social Psychology, 52, 384-389. 
Camerer, C., Loewenstein, G., \& Weber, M. (1989). The curse of knowledge in economic settings: An experimental analysis. The Journal of Political Economy, 97, 12321254.

Chance, Z., \& Norton, M. I. (2007). Decision amnesia: Why taking your time leads to forgetting. Unpublished manuscript, Harvard Business School.

Denno, D. W. (2003). A mind to blame: New views on involuntary acts. Behavioral Sciences and the Law, 21, 608-618.

Dijksterhuis, A. (2004). Think different: The merits of unconscious thought in preference development and decision making. Journal of Personality and Social Psychology, 87, 586-598.

Dijksterhuis, A., Chartrand, T., \& Aarts, H. (2007). Effects of priming and perception on social behavior and goal pursuit. In J. A. Bargh (ed.), Social Psychology and the Unconscious: The Automaticity of Higher Mental Processes. New York: Psychology Press.

Dijksterhuis, A., \& Nordgen, L. F. (2006). A theory of unconscious thought. Perspectives on Psychological Science, 1, 95-109.

Epley, N., Morewedge, C. K., \& Keysar, B. (2004). Perspective taking in children and adults: Equivalent egocentrism but differential correction. Journal of Experimental Social Psychology, 40(6), 760-768.

United States Sentencing Commission. (2004). Federal Sentencing Guidelines. Retrieved December 8, 2007, from http://www.ussc.gov/2004guid/2a1_1.htm.

Feinberg, T. E. (2001). Altered egos: How the brain creates the self. New York: Oxford University Press. 
Festinger, L. (1957). A theory of cognitive dissonance. Stanford, CA: Stanford University Press.

Fischhoff, B. (1975). Hindsight does not equal foresight: The effect of outcome knowledge on judgment under uncertainty. Journal of Experimental Psychology: Human Perception and Performance, 1, 288-299.

Fiske, S. (1989). Examining the role of intent: Toward understanding its role in stereotyping and prejudice. In J. S. Uleman and J. A. Bargh (eds.), Unintended Thought, (pp. 253-286). New York: Guilford press.

Förster, J., Liberman, N., \& Friedman, R. S. (2007). Seven principles of goal activation: A systematic approach to distinguishing goal priming from priming of non-goal constructs. Personality and Social Psychology Review, 11, 211-233.

Franco, F. M., \& Maass, A. (1999). Intentional control over prejudice: When the choice of the measure matters. European Journal of Social Psychology, 29, 469-477.

Gilbert, D. T. (1991). How mental systems believe. American Psychologist, 46, 107-119.

Gilbert, D. T., \& Malone, P. S. (1995). The correspondence bias. Psychological Bulletin, $117,21-38$.

Goethals, G. R., \& Reckman, R. F. (1973). The perception of consistency in attitudes. Journal of Experimental Social Psychology, 9, 491-501.

Gollwitzer, P. M. (1999). Implementation intentions: Strong effects of simple plans. American Psychologist, 54, 493-503.

Greenwald, A.G., Carnot, C.G., Beach, R., \& Young, B. (1987). Increasing voting behavior by asking people if they expect to vote. Journal of Applied Psychology, 72, 315-318. 
Haidt, J. (2001). The emotional dog and its rational tail: A social intuitionist approach to moral judgment. Psychological Review, 108(4), 814-834.

Harmon-Jones, E., \& Mills, J. (Eds.). (1999). Cognitive dissonance: Progress on a pivotal theory in social psychology. Washington, DC: American Psychological Association.

Hart, H. L. A., \& Honoré, T. (1959/2002). Causation and the law. New York: Oxford University Press.

Ichheiser, G. (1949). Misunderstandings in Human Relations: A Study in False Social Perception. Chicago: University of Chicago Press.

James, W. (1890/1955). The principles of psychology. Mineola, New York: Dover.

Johansson, P., Hall, L., Sikstrom, S., \& Olsson, A. (2005). Failure to detect mismatches between intention and outcome in a simple decision task. Science, 310(7), 116119.

Jones, E.E., \& Davis, K.E. (1965). From acts to dispositions: the attribution process in person perception. In L. Berkowitz (Ed.), Advances in Experimental Social Psychology. Vol. 2. New York: Academic Press, pp. 219-266.

Jones, E. E., \& Harris, V. A. (1967 ). The attribution of attitudes. Journal of Experimental Social Psychology, 3, 1-24.

Kadish, S. H., \& Schulhofer, S. J. (1995). Criminal law and its process: Cases and materials. Aspen Law \& Business.

Kahneman, D. and Frederick, S. (2002). Representativeness revisited: Attribute substitution in intuitive judgment. In T. Gilovich, D. Griffin, and D. Kahneman 
(eds), Heuristics \& Biases: The Psychology of Intuitive Judgment, pp. 49-81. New York: Cambridge University Press.

Kahneman, D., Schkade, D., \& Sunstein, C. R. (1998). Shared outrage and erratic awards: The psychology of punitive damages. Journal of Risk and Uncertainty, 16, 49-86.

Kelley, H. H. (1973). The processes of causal attribution. American Psychologist, 28, 107-128.

Klimchuck, D. (1994). Review: Outrage, self-control, and culpability. The University of Toronto Law Journal, 44, 441-468.

Kruger, J., \& Gilovich, T. (2004). Actions and intentions in self-assessments: The road to self-enhancement is paved with good intentions. Personality and Social Psychology Bulletin, 30, 328-339.

Krull, D. S. (1993). Does the grist change the mill? The effect of the perceiver's interferential goal in the process of social inference. Personality and Social Psychology Bulletin, 19, 340-348.

Langer, E. J. (1975). The illusion of control. Journal of Personality and Social Psychology, 32, 311-328.

Langer, E. J. (1983). The psychology of control. Beverly Hills, CA: Sage.

Langer, E. J. \& Roth, J. (1975). Heads I win, tails it's chance: The illusion of control as a function of the sequence of outcomes in a purely chance task. Journal of Personality and Social Psychology, 32, 951-955. 
Masicampo, E. J., \& Baumeister, R. F. (2008). Toward a physiology of dual-process reasoning and judgment: Lemonade, willpower, and expensive rule-based analysis. Psychological Science, 19, 255-260.

McFarland, C., Ross, M., \& DeCourville, N. (1989). Women's theories of menstruation and biases in recall of menstrual symptoms. Journal of Personality and Social Psychology, 57, 522-531.

Milgram, S. (1974). Obedience to Authority: An Experimental View. Harpercollins.

Miller, D. T., \& Ross, M. (1975). Self-serving biases in the attribution of causality: Fact or fiction? Psychological Bulletin, 82, 213-225.

Miller, D. T., Visser, P. S., Staub, B. D. (2005). How surveillance begets perceptions of dishonesty: The case of the counterfactual sinner. Journal of Personality and Social Psychology, 89, 117-128.

Morewedge, C. K., Gilbert, D. T., \& Wilson, T. D. (2005). The least likely of times: How remembering the past biases forecasts of the future. Psychological Science, 16(8), 626-630.

Morewedge, C. K., Preston, J., \& Wegner, D. M. (2007). Timescale bias in the attribution of mind. Journal of Personality and Social Psychology, 93, 1-11.

Morewedge, C. K., \& Wegner, D. M. (2008). The premeditation ritual: Going through the motions of thinking ahead. Manuscript in preparation, Carnegie Mellon University.

Morwitz, V.G., Johnson, E.J., \& Schmittlein, D. (1993). Does measuring intent change behavior? Journal of Consumer Research, 20, 46-61. 
Nisbett, R. E., \& Wilson, T. D. (1977). Telling more than we can know: Verbal reports on mental processes. Psychological Review, 84(3), 231-259.

Pieters, R., Baumgartner, H., \& Bagozzi, R. (2006). Biased memory for prior decision making: Evidence from a longitudinal field study. Organizational Behavior and Human Decision Processes, 99, 34-48.

Pizarro, D. A., Uhlmann, E., \& Bloom, P. (2003). Causal deviance and the attribution of moral responsibility. Journal of Experimental Social Psychology, 39, 653-660.

Pizarro, D. A., Uhlmann, E., \& Salovey, P. (2003). Asymmetry in judgments of moral blame and praise: The role of perceived metadesires. Psychological Science, 14(3), 267-272.

Preston, J., \& Wegner, D. M. (2007). The eureka error: Journal of Personality and Social Psychology, 92, 575-584.

Pronin, E., Gilovich, T., \& Ross, L. (2004). Objectivity in the eye of the beholder: Divergent perceptions of bias in self versus others. Psychological Review, 111(3), 781-799.

Pronin, E., Wegner, D. M., McCarthy, K., \& Rodriguez, S. (2006). Everyday magical powers: The role of apparent mental causation in the overestimation of personal influence. Journal of Personality and Social Psychology, 91, 218-231.

Radin, D. I. (2006). Psychophysical evidence of possible retrocausal effects in humans. In D. P. Sheehan (Ed.), Frontiers of Time, Retrocausation-Experiment and Theory (pp. 193-213). New York: Springer-Verlag.

Ross, L. D., \& Nisbett, R. E. (1991). The person and the situation: Perspectives of social psychology. New York: McGraw-Hill. 
Schacter, D. L., \& Addis, D. R. (2007). The cognitive neuroscience of constructive memory: Remembering the past and imagining the future. Philosophical Transactions of the Royal Society: Biological Sciences, 362, 773-786.

Schwartz, B., Ward, A., Monterosso, J., Lyubomirsky, S., White, K., \& Lehman, D. R. (2003). Maximizing versus satisficing: Happiness is a matter of choice. Journal of Personality and Social Psychology, 83, 1178-1197.

Shaver, K. G. (1985). The attribution of blame: Causality, responsibility, and blameworthiness. New York: Springer-Verlag.

Shiv, B., \& Fedorikhin, A. (1999). Heart and mind in conflict: Interplay of affect and cognition in consumer decision making. Journal of Consumer Research, 26, 278282.

Simon, H. A. (1957). Models of man, social and rational: Mathematical essays on rational human behavior. New York: Wiley.

Spranca, M., Minsk, E., \& Baron, J. (1991). Omission and commission in judgment and choice. Journal of Experimental Social Psychology,

Tversky, A., \& Kahneman, D. (1973). Availability: A heuristic for judging frequency and probability. Cognitive Psychology, 5, 207-232.

Vohs, K. D., \& Faber, R. J. (2007). Spent resources: Self-regulatory resource availability affects impulse buying. Journal of Consumer Research, 33, 537-547.

Vohs, K. D., \& Schooler, J. W. (2008). The value of believing in free will: Encouraging a belief in determinism increases cheating. Psychological Science, 19, 49-54.

von Neumann, J., \& Morgenstern, O. (1944). Theory of games and economic behavior. Princeton: Princeton University Press. 
Wegner, D. M. (1994). Ironic processes of mental control. Psychological Review, 101, 34-52.

Wegner, D. M. (2002). The illusion of conscious will. Cambridge, MA: MIT Press.

Wegner, D. M. (2003). The mind's best trick: How we experience conscious will. Trends in Cognitive Sciences, 7, 65-69.

Wegner, D. M., Fuller, V. A., \& Sparrow, B. (2003). Clever hands: Uncontrolled intelligence in facilitated communication. Journal of Personality and Social Psychology, 85, 5-19.

Wegner, D. M., \& Wheatley, T. P. (1999). Apparent mental causation: Sources of the experience of will. American Psychologist, 54, 480-492.

Wheatley, T. \& Haidt, J. (2005). Hypnotic disgust makes moral judgments more severe. Psychological Science, 16, 780-784.

Weiner, B. (1995). Judgments of responsibility: A foundation for a theory of social conduct. New York: Guilford Press.

Wells, G. L., \& Gavinsky, I. (1989). Mental simulation of causality. Journal of Personality and Social Psychology, 56, 161-169.

Wimmer, H., \& Perner, J. (1983). Beliefs about beliefs: Representation and constraining function of wrong beliefs in young children's understanding of deception. Cognition, 13, 103-128.

Winkielman, P., \& Schwarz, N. (2001). How pleasant was your childhood? Beliefs about memory shape inferences from experienced difficulty of recall. Psychological Science, 12, 176-179. 
Woolfolk, R. L., Doris, J. M., \& Darley, J. M. (2006). Identification, situational constraint and social cognition: Studies in the attribution of moral responsibility. Cognition, 100, 283-301.

Zanna, M. P., \& Cooper, J. (1974). Dissonance and the pill: An attribution approach to studying the arousal properties of dissonance. Journal of Personality and Social Psychology, 29, 703-709. 


\section{Ideal Premeditation}

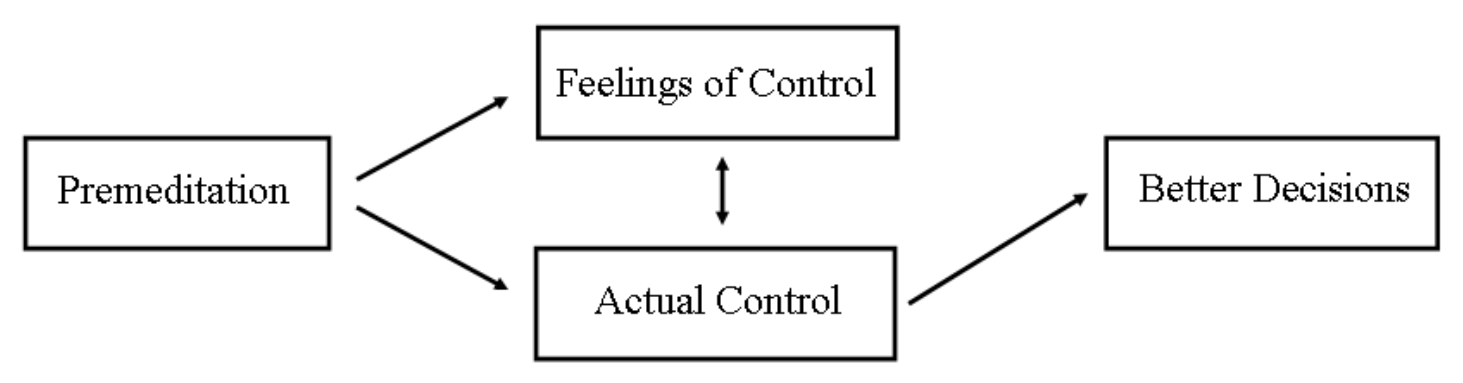

\section{Actual Premeditation}

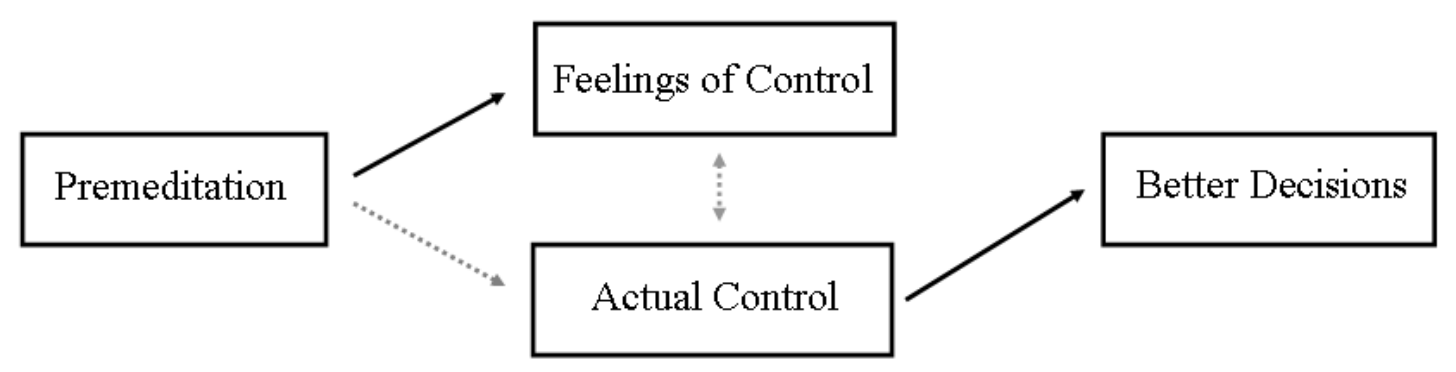

Figure 1. The diagram above depicts ideal premeditation, as conceived of by society and the law. It assumes that premeditation influences both feelings of control and actual control to a similar degree, resulting in better decisions. An alternative, actual premeditation, is presented in the diagram beneath it. It suggests that premeditation influences feelings of control, but may not influence one’s actual control over decision or lead to better decisions. 
Standard Previews/Post-views:

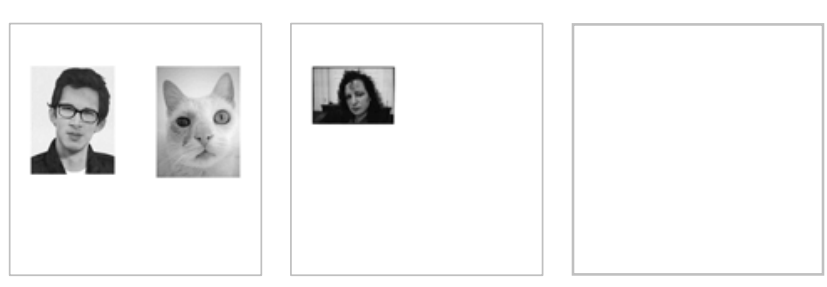

Distorted Previews:

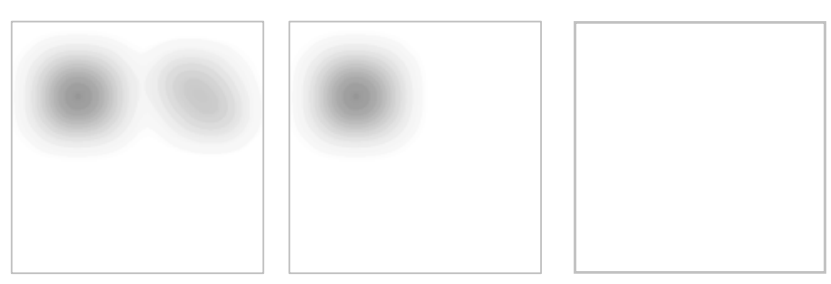

Figure 2. Examples of previews and post-views depicting two, one, and no works of art that were used in art selection experiments appear in the top row. Examples of distorted previews appear in the bottom row. Each preview was 100 pixels wide and presented 25 pixels from the center of a 17” monitor with a resolution of $1028 x 768$. 